\title{
Detection of bioavailable cadmium, lead, and arsenic in polluted soil by tailored multiple Escherichia coli whole-cell sensor set
}

\author{
Qihui Hou ${ }^{1,2}$ • Anzhou Ma ${ }^{1}$ - Thanh Wang ${ }^{3}$ - Jianqiang Lin ${ }^{4} \cdot$ Hailin Wang ${ }^{3}$. \\ Binghai Du ${ }^{2} \cdot$ Xuliang Zhuang ${ }^{1} \cdot$ Guoqiang Zhuang ${ }^{1}$
}

Received: 30 March 2015 /Revised: 18 May 2015 / Accepted: 5 June 2015 /Published online: 3 July 2015

(C) Springer-Verlag Berlin Heidelberg 2015

\begin{abstract}
Microbial whole-cell sensor has been widely used to assess bioavailability and risk of toxic elements, but their environmental use is still limited due to the presence of other interfering pollutants and the nonspecific binding in cells, which leads to inaccurate results. Here, we proposed a strategy combining Escherichia coli sensor set with binary regression models for the specific detection of bioavailable cadmium $(\mathrm{Cd})$, lead $(\mathrm{Pb})$, and arsenic $(\mathrm{As})$ in a co-polluted environment. Initial tests suggested that the sensor set respectively termed pcadCluc, pzntRluc, and parsRluc could be classified into two groups according to their specific response to $\mathrm{Cd}, \mathrm{Pb}$, and $\mathrm{As}$ : group 1 (pcadCluc and pzntRluc) induced by a $\mathrm{Cd}-\mathrm{Pb}$ mix and group 2 (parsRluc) induced by a Cd-As mix. Based on the variance in responses of each sensor to mixtures of target elements, three binary linear equations for two sensor groups were set up to calculate the individual concentrations in the
\end{abstract}

Electronic supplementary material The online version of this article (doi:10.1007/s00216-015-8830-z) contains supplementary material, which is available to authorized users.

Anzhou Ma

azma@rcees.ac.cn

Guoqiang Zhuang

gqzhuang@rcees.ac.cn

1 Key Laboratory of Environmental Biotechnology, Research Center for Eco-Environmental Sciences, Chinese Academy of Sciences, Beijing 100085, China

2 College of Life Sciences, Shandong Agricultural University, Tai'an 271018, China

3 State Key Laboratory of Environmental Chemistry and Ecotoxicology, Research Center for Eco-Environmental Sciences, Chinese Academy of Sciences, Beijing 100085, China

4 State Key Laboratory of Microbial Technology, Shandong University, Jinan 250100, China mixture solutions. This method was then used to quantify the bioavailable $\mathrm{Cd}, \mathrm{Pb}$, and As in soils from a co-polluted mining region and to compare the results with other methods. Results showed that the conventional single target sensor method overestimated the bioavailability of each element, while sensor set was credible for accurate bioavailable $\mathrm{Cd}, \mathrm{Pb}$, and $\mathrm{As}$ quantification and comparable with the results from inductively coupled plasma mass spectrometry (ICP-MS) analysis. Our method can potentially be extended to cover the specific detection of other bioavailable toxic elements in different environmental settings.

Keywords Heavy metals · Bioavailability · Specificity · Whole-cell sensor set $\cdot$ Cross-mixed induction $\cdot$ Binary linear regression

\section{Introduction}

Cadmium $(\mathrm{Cd})$, lead $(\mathrm{Pb})$, and arsenic (As) contamination are attracting continuing concern in many parts of the world due to their high content in agricultural products, high toxicity, and accumulation in the human body. Chemical analysis based on a series of analytical instrumentations such as Atomic Absorption Spectroscopy (AAS) and inductively coupled plasma mass spectrometry (ICP-MS) can give accurate and sensitive determination of the total metal content in the environment. However, due to the sorption and complexation of trace elements in soil, only a fraction of the total content is available for uptake to biota. The associated environmental risk of hazardous elements in polluted environments might therefore be more accurately determined from their bioavailable fraction. Bioavailable metal can be defined as the metal fraction available for crossing an organism's cell membrane [1], so it not only evaluates soluble metals but also those in other chemical 
forms which can cross the cell membrane. Chemical-assessing methods such as single chemical extraction or sequential extraction procedures (SEPs) are frequently employed to quantify the bioavailable metals. However, these calculated bioavailable fractions do not correlate well with actual bioavailability because these were obtained using non-biological protocols. For instance, bioavailable $\mathrm{Cd}$ extracted by weak acid in polluted field soils was dozens of times higher than that determined using a microbial whole-cell sensor and the amount of $\mathrm{Pb}$ in sequential leaches was obviously different with microbial whole-cell sensor-determined $\mathrm{Pb}[2,3]$.

Whole-organism assay is an effective approach to assess actual biological response, bioavailability, and toxicity of metals in soil. Numerous microbial whole-cell sensors have been developed to measure the soil bioavailability of toxic elements such as $\mathrm{Cd}, \mathrm{Pb}, \mathrm{As}, \mathrm{Hg}$, and $\mathrm{Cr}[4,5]$. However, almost all the developed whole-cell sensors are nonspecific to a certain metal since the regulatory proteins, such as $\mathrm{CadC}$, ZntR, and ArsR, could concurrently recognize several different metals $[6,7]$. Nonspecific microbial sensors that respond to multiple metals in a certain environment will tend to overestimate the bioavailability of target metals and environmental risks in a co-polluted environment.

In order to realize the specific and accurate detection of bioavailable $\mathrm{Cd}, \mathrm{Pb}$, and $\mathrm{As}$ in a co-polluted environment, a multiple Escherichia coli whole-cell sensor set and binary linear equations were built in this study to eliminate the interference between $\mathrm{Cd}, \mathrm{Pb}$, and $\mathrm{As}$ by a series of experiment procedures such as specificity analysis, sensor grouping, and mixture induction. The test of soil samples showed that this method was more feasible for detecting bioavailable metals compared to using single whole-cell sensors in a co-polluted environment, which tend to overestimate the levels.

\section{Experimental}

\section{Materials and methods}

Vent DNA polymerase, restriction endonucleases, and T4 ligase were purchased from NEB (USA). $\mathrm{CdSO}_{4}, \mathrm{PdSO}_{4}$, and $\mathrm{NaAsO}_{2}$ were purchased from the National Research Center for Certified Reference Material, China. Oligo primer (see Electronic Supplementary Material (ESM) Table S1) synthesis and sequencing were performed by Invitrogen (China).

\section{E. coli whole-cell $\mathrm{Cd}, \mathrm{Pb}$, and As sensors}

The parsRluc (see ESM Fig. S1a) and pcadCluc (ESM Fig. S1b) sensors were constructed in the previous research by our laboratory $[8,9]$. The pzntRluc sensor (ESM Fig. S1c) was constructed by this study as follows: The Pznt promoter was amplified using the primers Pznt-F/Pznt-R and linked to the upstream of luc in pUC18luc [8], which was then digested using SacI and XhoI. Next, the primers PnptII-F/PnptII-R, Pznt-R-F/Pznt-R-R, and PrrNB-F/PrrNB-R were used to construct constitutively expressed zntR (NC_007779) fragment from $E$. coli $\mathrm{DH} 5 \propto$ (Biomed, China). The restriction enzyme sites at the ends of the $z n t R$ fragment were then changed from $B a m \mathrm{HI}$ and EcoRI to SacI using the P1 and P2 primers, and the resulting fragment was reversely linked to pUC18luc.

\section{Soil samples}

Soil samples were obtained from the Shuikoushan mining area in Hengyang City, Hunan Province, China. Detailed information about the soil samples is shown in ESM Table S2.

\section{Specificity analysis of sensors to $\mathrm{Cd}, \mathrm{Pb}$, and $\mathrm{As}$}

Standard induction assays [8] for the pcadCluc, pzntRluc, and parsRluc sensors were performed to determine their specificity to $\mathrm{Cd}, \mathrm{Pb}$, and As. Relative luminescence units (RLUs) were measured using the GloMax-Multi microplate multimode reader (Promega, USA). The induction experiment of sensor cells $\left(\mathrm{OD}_{600}=0.6-0.8\right)$ by standard metal solution and RLU measure respectively took $2 \mathrm{~h}$ and $30 \mathrm{~min}$.

\section{Construction of binary linear equation groups}

$\mathrm{Cd}^{2+}-\mathrm{Pb}^{2+}$ and $\mathrm{Cd}^{2+}-\mathrm{As}^{3+}$ induction experiments

Standard $\mathrm{Cd}^{2+}$ and $\mathrm{Pb}^{2+}$ solutions of equal volumes $(25 \mu \mathrm{L})$ and concentrations $(0,0.4,0.5,1,1.5,2,4,6,8$, and $20 \mu \mathrm{M})$ were cross-mixed and then used to induce pcadCluc and pzntRluc in the 96-well plates. Similarly, standard of $\mathrm{As}^{3+}$ $(0,0.4,0.5,1,1.5,2,4,6,8$, and $20 \mu \mathrm{M})$ and $\mathrm{Cd}^{2+}(0,20$, $22,24,28,32,40,48,56$, and $80 \mu \mathrm{M})$ solutions of equal volumes $(25 \mu \mathrm{L})$ were cross-mixed and used to induce parsRluc. Three-dimensional diagrams of RLU variation with mixtures of the toxic elements were generated using Origin 8.0. Three replicate experiments were conducted for each experimental condition.

\section{Linear response analysis of sensors to mixed metals}

In order to better describe the analysis procedure, mixed metals $\left(\mathrm{Cd}^{2+}-\mathrm{Pb}^{2+}\right.$ or $\left.\mathrm{Cd}^{2+}-\mathrm{As}^{3+}\right)$ were set as metal $\mathrm{A}$ and metal B. Then, $k$ was defined as the slope of RLU at different initial metal A and increasing metal $\mathrm{B}$. The relationship between RLU and the concentrations of mixture metals was expressed as variational $k$ at different initial metal A. If the increase of $k$ was linear at a certain concentration range of metal $\mathrm{A}$, this range was set as the range in which metal $\mathrm{A}$ could induce a linear increase of RLU at the presence of metal B. All the six linear ranges were also determined by this way. 
At last, binary linear equations were then generated using MATLAB R2013a according to the results of mixture induction experiments and the linear response ranges.

\section{Detection of the bioavailable concentration of $\mathrm{Cd}, \mathrm{Pb}$, and As in soil}

The digestion of total $\mathrm{Cd}, \mathrm{Pb}$, and $\mathrm{As}$ was carried out using aqua regia $\left(\mathrm{HCl} / \mathrm{HNO}_{3}=3: 1\right.$ in $\left.v / v\right)$ and $\mathrm{HClO}_{4}$. Total As concentration of digested solution was detected by ICP-MS (Plasma Quad 3; UK). Soil water extracts were prepared according to the pre-existing method [10]. Serial dilutions of the soil water extracts were then performed to ensure that their total metal concentrations were within the range of detection of the single sensor and sensor groups. A pUC18NLR plasmid in E. coli DH5 $\alpha$, which constitutively expresses luc under the nptII promoter, was used as a positive control to detect possible spurious toxicity in the samples which may significantly interfere $(P>0.05)$ with the analysis.

\section{Results and discussion}

\section{Specificities of sensor regulators to $\mathrm{Cd}, \mathrm{Pb}$, and $\mathrm{As}$}

Specificity analysis showed that the RLU of both pcadCluc and pzntRluc sensors increased with $\mathrm{Cd}^{2+}$ and $\mathrm{Pb}^{2+}$ concentration but not significantly increased with $\mathrm{As}^{3+}$ concentration (Fig. 1a, b). For the parsRluc sensor, the RLU just significantly increased with both $\mathrm{Cd}^{2+}$ and $\mathrm{As}^{3+}$ concentration, although the RLU increase induced by $\mathrm{Cd}^{2+}$ was not as prominent as that induced by $\mathrm{As}^{3+}$ (Fig. 1c). These results indicated that, when the individual pcadCLuc, pzntRluc, or parsRluc sensors were used with mixed Cd$\mathrm{Pb}$-As solution, $\mathrm{Cd}$ and $\mathrm{Pb}$ may mutually interfere their respective measured results and $\mathrm{Cd}$ may affect the measured result of As. These findings are consistent with those of previous studies, which also observed nonspecific binding of metals such as $\mathrm{Cd}$ and $\mathrm{Pb}$ to $\mathrm{CadC} ; \mathrm{Pb}, \mathrm{Cd}, \mathrm{Hg}$, and $\mathrm{Zn}$ to $\mathrm{ZntR}$; and $\mathrm{As}$ and $\mathrm{Sb}$ to ArsR $[6,7]$.

The detection limit was determined using statistically significant changes $(P<0.05)$ in RLU compared with background RLU [11]. The detection limit of both pcadCluc and pzntRluc sensors for $\mathrm{Cd}$ and $\mathrm{Pb}$ was lower than 0.1 and $0.05 \mu \mathrm{M}$, respectively. The detection limit of parsRluc sensor for $\mathrm{Cd}$ and As was $5.0 \mu \mathrm{M}$ and lower than $0.1 \mu \mathrm{M}$, respectively. These results suggested that, when a non-target metal concentration was higher than the detection limit of sensor for target metal determination, overestimation would occur when a single cell sensor was used.

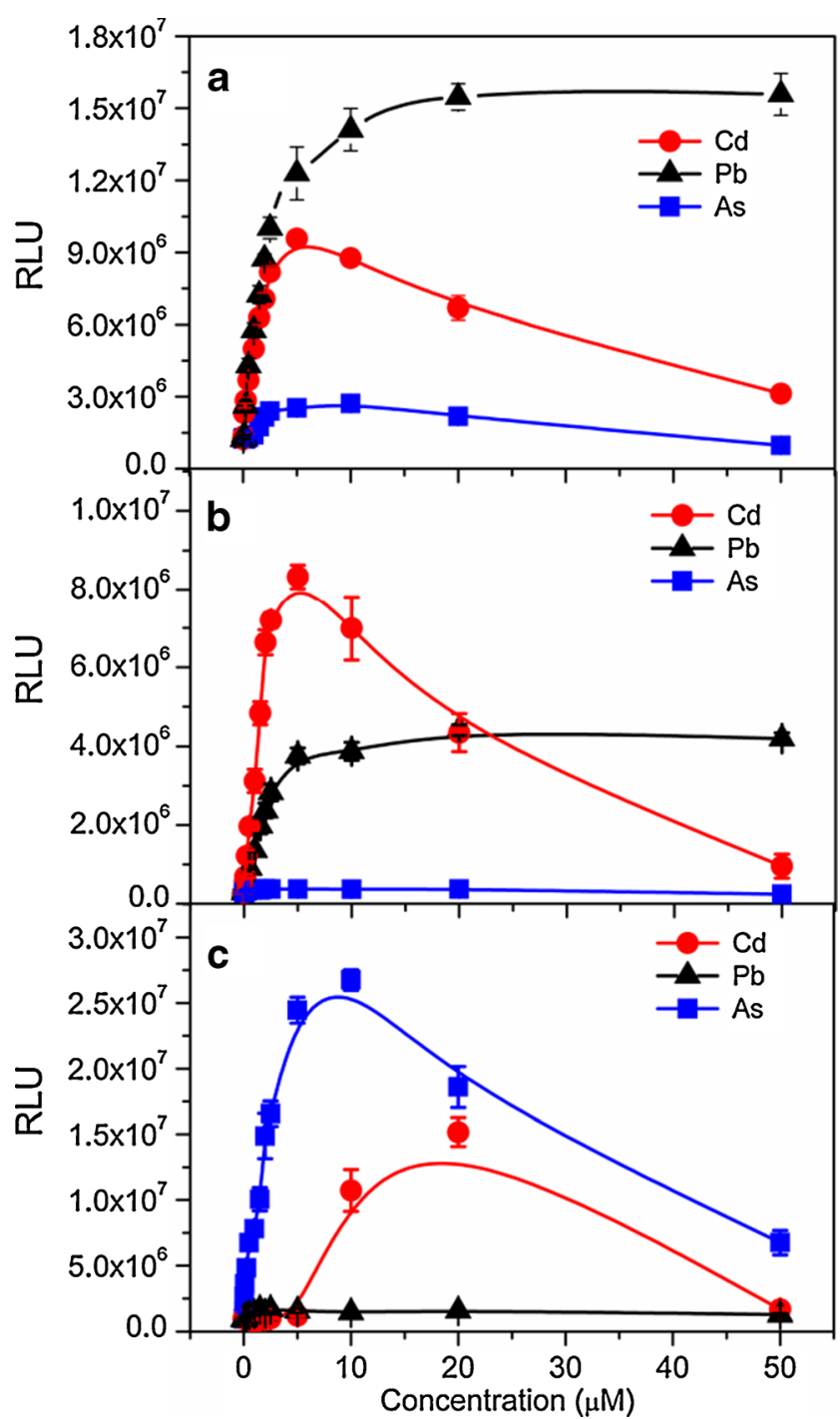

Fig. 1 Dose-response curves of pcadCluc (a), pzntRluc (b), and parsRluc (c) sensors to $\mathrm{Cd}, \mathrm{Pb}$, and As. Error bars mean the standard deviations of the three individual results

\section{Sensor set responses to mixtures of toxic elements}

Although interferences by the different elements occur, the response strength of each sensor to the same mixture solution is different. This means that the interferences can be distinguished by applying a set of sensors in combination with statistical analysis treatment.

According to the results of specificity analysis, the sensor set was divided into two groups: group 1 comprised of pcadCluc and pzntRluc sensors in order to distinguish the interference of $\mathrm{Cd}$ and $\mathrm{Pb}$, and group 2 comprised of parsRluc sensor, associated with group 1, to detect the specific bioavailable As. Three-dimensional mesh plots (ESM Fig. S2) showed that a mixture of 0.1 to $2.0 \mu \mathrm{M} \mathrm{Cd}-\mathrm{Pb}$ significantly induced pcadCluc and resulted in a RLU that was much higher than that induced by either $\mathrm{Cd}$ or $\mathrm{Pb}$ alone. Similarly, 0.1 to $2.0 \mu \mathrm{M} \mathrm{Cd}-\mathrm{Pb}, 5.0$ to $10.0 \mu \mathrm{M} \mathrm{Cd}$, and 0.1 to $2.0 \mu \mathrm{M} \mathrm{As}$ 
mixtures noticeably induced pzntRluc and parsRluc, respectively. The concentration ranges of mixed $\mathrm{Cd}-\mathrm{Pb}$ or $\mathrm{As}-\mathrm{Cd}$ that could linearly increase the RLU of each sensor were confirmed using parameter $k$ (Table 1).

\section{Mathematical treatment to determine specific concentration}

For eliminating the interferences between $\mathrm{Cd}, \mathrm{Pb}$, and As to sensors, binary linear regression (Fig. 2) and equations (Eqs. 1, 2, 3) were established by MATLAB R2013a on the basis of grouping and concentration ranges of mixed metals that could linearly increase the RLU of sensor group. For sensor group 1, the overlapping concentration ranges $(0.1-1.0 \mu \mathrm{M})$ of mixed $\mathrm{Cd}$ and $\mathrm{Pb}$ were determined according to their concentration ranges, linearly increasing the RLU of each sensor (Table 1).

Sensor group 1:

$$
\left\{\begin{array}{lll}
\mathrm{RLU}_{\mathrm{pcadCluc}}=33.01 \mathrm{E} 5 \cdot c_{\mathrm{Cd}}+49.72 \mathrm{E} 5 \cdot c_{\mathrm{Pb}}+22.42 \mathrm{E} 5 & R^{2}=0.99 & \left(c_{\mathrm{Pb}}: 0.1-1.0 \mu \mathrm{M}\right) \\
& \left(c_{\mathrm{Cd}}: 0.1-1.0 \mu \mathrm{M}\right) \\
\mathrm{RLU}_{\mathrm{pzntRluc}}=26.99 \mathrm{E} 5 \cdot c_{\mathrm{Cd}}+11.96 \mathrm{E} 5 \cdot c_{\mathrm{Pb}}+5.94 \mathrm{E} 5 & R^{2}=0.97 & \left(c_{\mathrm{Pb}}: 0.1-1.0 \mu \mathrm{M}\right) \\
& \left(c_{\mathrm{Cd}}: 0.1-1.0 \mu \mathrm{M}\right)
\end{array}\right.
$$

Sensor group 2:

$$
\begin{aligned}
\mathrm{RLU}_{\text {parsRluc }} & =79.57 \mathrm{E} 5 \cdot c_{\mathrm{As}}+8.85 \mathrm{E} 5 \cdot c_{\mathrm{Cd}}-9.84 \mathrm{E} 5 ; R^{2} \\
& =0.97\left(c_{\mathrm{As}}=0.1-1.0 \mu \mathrm{M} ; c_{\mathrm{Cd}}=5.0-10.0 \mu \mathrm{M}\right)
\end{aligned}
$$

The significance test of equations was illustrated in ESM Text S1. For comparisons, regressions for single sensors to measure bioavailable concentrations of $\mathrm{Cd}, \mathrm{Pb}$, and $\mathrm{As}$ in individual standard solutions are also presented in Eqs. 4, 5, and 6 .

Cd detection by pcadCluc:

$$
\begin{aligned}
\mathrm{RLU}_{\mathrm{pcadCluc}} & =2.7 \mathrm{E} 6 \cdot c_{\mathrm{Cd}}+2.12 \mathrm{E} 6 ; \\
R^{2} & =0.99(\mathrm{Cd}=0.1-1.0 \mu \mathrm{M})
\end{aligned}
$$

$\mathrm{Pb}$ detection by pzntRluc:

$$
\begin{aligned}
\operatorname{RLU}_{\text {pzntRluc }} & =7.54 \mathrm{E} 5 \cdot c_{\mathrm{Pb}}+4.68 \mathrm{E} 5 ; R^{2} \\
& =0.97(\mathrm{~Pb}=0.1-1.0 \mu \mathrm{M})
\end{aligned}
$$

As detection by parsRluc:

$$
\begin{aligned}
\mathrm{RLU}_{\text {parsRluc }} & =4.2 \mathrm{E} 6 \cdot c_{\text {As }}+3.5 \mathrm{E} 6 ; R^{2} \\
& =0.98(\mathrm{As}=0.1-1.0 \mu \mathrm{M})
\end{aligned}
$$

\section{Bioavailable concentrations of $\mathrm{Cd}, \mathrm{Pb}$, and $\mathrm{As}$ in soil samples}

Among the 24 soil samples, only water-soluble $\mathrm{Cd}$ and $\mathrm{Pb}$ in $\mathrm{P} 1-\mathrm{P} 7$ were $0.2-15.8 \mathrm{mg} / \mathrm{kg}(0.2-15.6 \mu \mathrm{M})$ and $0.3-$ $23.2 \mathrm{mg} / \mathrm{kg}(1.6-12.4 \mu \mathrm{M})$, respectively, and water-soluble

Table 1 Mixed metal concentration ranges for linear sensor response ( $k=$ the slope of RLU at different initial metal A and increasing metal B)

\begin{tabular}{llllllll}
\hline & Sensor & Metal A & Metal B & $\begin{array}{l}\text { Linear equation of } k \text { variation }(y) \\
\text { with increasing metal A }(x)\end{array}$ & $R^{2}$ & $\begin{array}{l}\text { Concentration range of } \\
\text { metal A }(x)(\mu \mathrm{M})\end{array}$ & Detection limit $(\mu \mathrm{M})$ \\
\hline \multirow{2}{*}{ Sensor group 1 } & \multirow{2}{*}{ pcadCluc } & $\mathrm{Pb}$ & $\mathrm{Cd}$ & $y=7.94 \mathrm{E} 5 x+3.48 \mathrm{E} 6$ & $0.86^{* *}$ & $0.1-1.0$ & $\mathrm{~Pb}=0.1-1.0$ \\
& & $\mathrm{Cd}$ & $\mathrm{Pb}$ & $y=9.63 \mathrm{E} 5 x+4.77 \mathrm{E} 6$ & $0.98^{* *}$ & $0.1-1.0$ & $\mathrm{Cd}=0.1-1.0$ \\
& \multirow{2}{*}{ pzntRluc } & $\mathrm{Cd}$ & $\mathrm{Pb}$ & $y=9.78 \mathrm{E} 5 x+8.82 \mathrm{E} 5$ & $0.97^{* *}$ & $0.1-1.0$ & $0.95^{* *}$ \\
& & $\mathrm{~Pb}$ & $\mathrm{Cd}$ & $y=7.51 \mathrm{E} 5 x+2.76 \mathrm{E} 6$ & $0.1-1.5$ & $\mathrm{As}=0.1-1.0$ \\
Sensor group 2 & \multirow{2}{*}{ parsRluc } & $\mathrm{As}$ & $\mathrm{Cd}$ & $y=1.48 \mathrm{E} 5 x+3.87 \mathrm{E} 6$ & $0.1-1.0$ & $\mathrm{Cd}=5.0-10.0$ \\
& & $\mathrm{Cd}$ & $\mathrm{As}$ & $y=1.48 \mathrm{E} 5 x+1.40 \mathrm{E} 6$ & $0.90^{* *}$ & $5.0-10.0$ & \\
\hline
\end{tabular}

$* * P<0.01$ 
As in P2 and P5 was $0.7-1.2 \mathrm{mg} / \mathrm{kg}(0.1-1.7 \mu \mathrm{M})$, which were respectively higher than the detection limit of pcadCluc, pzntRluc, and parsRluc sensors. Therefore, the bioavailability
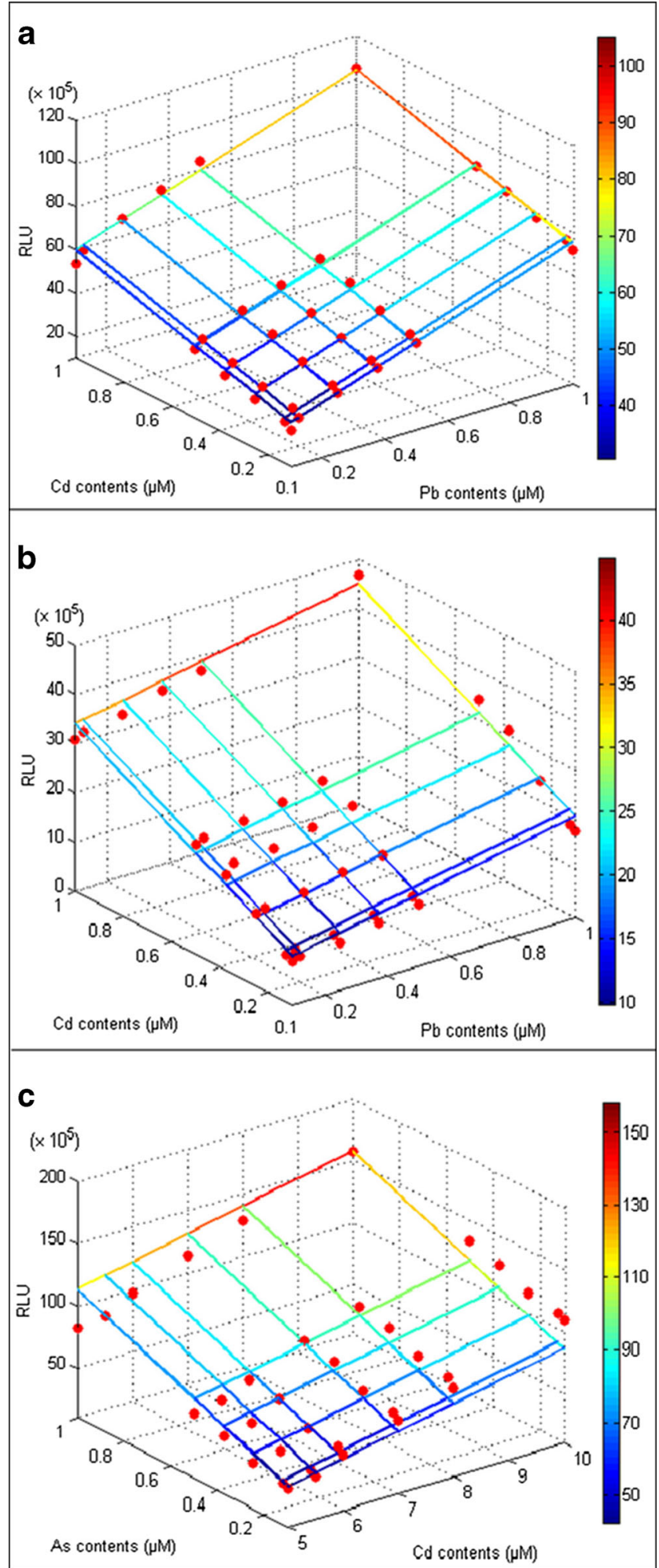

Fig. 2 Binary linear regressions of pcadCluc (a) and pzntRluc (b) sensors in group 1 to $\mathrm{Cd}-\mathrm{Pb}$ mixtures and of parsRluc (c) sensor in group 2 to As-Cd mixtures of $\mathrm{Cd}$ and $\mathrm{Pb}$ in samples $\mathrm{P} 1-\mathrm{P} 7$ and that of $\mathrm{As}$ and $\mathrm{Cd}$ in sample P2 and P5 could be evaluated respectively by sensor groups 1 and 2 since the total metal concentrations of soil water extractions would be in the independent variable ranges of binary linear regression equations after dilution. In addition, the total content of $\mathrm{Cd}, \mathrm{Pb}$, and $\mathrm{As}$ in the selected samples ranged from 13.2 to $68.4 \mathrm{mg} / \mathrm{kg}$, from 216.6 to $8868.1 \mathrm{mg} / \mathrm{kg}$, and from 268.9 to $442.2 \mathrm{mg} / \mathrm{kg}$, respectively, which were respectively 16 to 85 -fold, 2 to 110 -fold, and 3 to 9 -fold higher
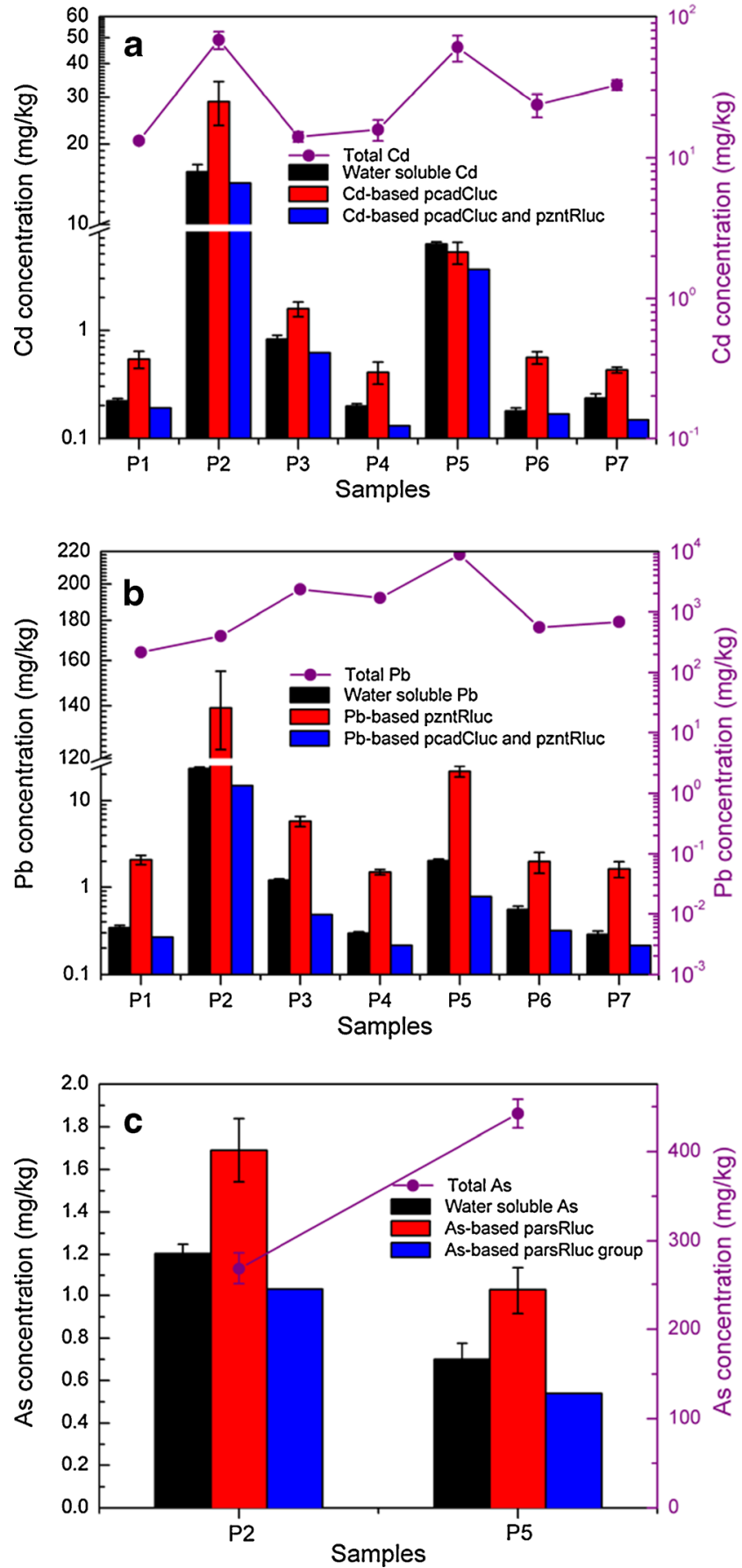

Fig. $3 \mathrm{Cd}(\mathbf{a}), \mathrm{Pb}(\mathbf{b})$, and $\mathrm{As}(\mathbf{c})$ concentrations in soil samples $\mathrm{P} 1-\mathrm{P} 7$. Error bars mean the standard deviations of the three individual results 
than the quality standard of agricultural land in China (GB15618-2008). Hence, all the seven soil samples were seriously polluted by $\mathrm{Cd}, \mathrm{Pb}$, and $\mathrm{As}$ as judged using the quality standard.

When the conventional single whole-cell sensor was used to measure these environmental samples, with the exception of $\mathrm{Cd}$ in $\mathrm{P} 5$, the bioavailable concentrations of $\mathrm{Cd}, \mathrm{Pb}$, and $\mathrm{As}$ were higher than their corresponding total water-soluble concentrations (Fig. 3) due to the presence of multiple interferents and the sensors' non-specificity. Statistically, the bioavailable concentrations of $\mathrm{Cd}, \mathrm{Pb}$, and As were respectively 1.45 3.34-fold, 6.61-27.67-fold, and 1.6-2.02-fold of their corresponding total water-soluble concentrations. Results also showed that the effect of sample impurity in soil water extractions on bioluminescence emission of sensor could be negligible (ESM Table S3). Obviously, because of the nonspecific response of core regulator protein, the results, especially the bioavailable $\mathrm{Pb}$, were interfered and overrated by other metals. The interference strength can also be demonstrated by the coefficient ratio in Eqs. 1-3, in which it (coefficient $c_{\mathrm{pb}} /$ coefficient $_{\mathrm{cd}}$, coefficient $c_{\mathrm{cd}} /$ coefficient $_{\mathrm{pb}}$, coefficient $c_{\mathrm{cd}} /$ coefficient $_{\mathrm{As}_{\mathrm{As}}}$ ) was $1.51,2.26$, and 0.11 , respectively. Therefore, the strength order of suffered interference in the three single sensors was

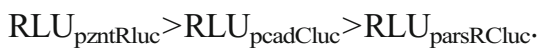

In contrast, the $\mathrm{Cd}$ bioavailable concentration determined using group 1 (pcadCluc and pzntRluc) was 29.6-69.8\% (mean $41.3 \%$ ) of that determined using pcadCluc alone, and the $\mathrm{Pb}$ bioavailable concentration determined using group 1 (pcadCluc and pzntRluc) was 8.4-16.0\% (mean 11.2\%) of that determined using pzntRluc alone. Similarly, the As bioavailable concentration determined using group 2 (parsRluc) in $\mathrm{P} 2$ and $\mathrm{P} 5$ was 60.9 and $52.9 \%$ (mean $56.9 \%$ ), respectively, of that determined using parsRluc alone (Fig. 3). These results indicated that, with the single sensor, the $\mathrm{Pb}$ bioavailability was significantly overestimated by the Cd interference, whereas the $\mathrm{Cd}$ and As bioavailability was partly overestimated by the interference of $\mathrm{Pb}$ and $\mathrm{Cd}$. However, with the sensor set, the specific determination of bioavailable $\mathrm{Cd}, \mathrm{Pb}$, and As could be realized and this can provide a significant step towards accurately assessing the actual bioavailable concentration of each toxic element in a co-polluted environment.

The bioavailable concentrations of $\mathrm{Cd}, \mathrm{Pb}$, and $\mathrm{As}$ determined using the sensor groups were lower than their corresponding total water-soluble concentrations, and these results also supported that the bioavailable concentration of $\mathrm{Cd}, \mathrm{Pb}$, and As determined with the sensor set was effective and dependable. In detail, the fractions of $\mathrm{Cd}, \mathrm{Pb}$, and $\mathrm{As}$ that are bioavailable, according to the sensor groups, were 59.1-90.7, $38.2-78.1$, and $77.1-85.8 \%$, respectively, of their total watersoluble contents for P1 to P7. These findings are not unexpected since they can be explained by the presence of metal chelator in the soil water extraction, such as dissolved organic matter and other metal chelators, which could sorb or bind heavy metals but non-bioavailable, thereby decreasing their bioavailability [12-14].

\section{Conclusion}

Based on the conventional whole-cell sensor technique, we developed a novel method that could effectively distinguish and eliminate the interference of multiple elements $(\mathrm{Cd}, \mathrm{Pb}$, and As) with tailored microbial whole-cell sensor set, and then applied this for the specific and accurate detection of bioavailable $\mathrm{Cd}, \mathrm{Pb}$, and $\mathrm{As}$. The test results that indicated actual bioavailable $\mathrm{Cd}, \mathrm{Pb}$, and As calculated using a sensor set were $41.3,11.2$, and $56.9 \%$, respectively, of the value calculated using a single sensor. In addition, the results based on a sensor set were comparable with the results from ICP-MS analysis. This method could be a significant improvement for the rapid assessment of the actual bioavailability and risk of toxic element in co-polluted environments. The exhaustive arithmetical process we used can also be adapted to measure other heavy metals such as $\mathrm{Hg}, \mathrm{Zn}$, and $\mathrm{Cu}$, in complex soil and water samples.

Acknowledgments This work is financially supported by the "Knowledge Innovation" Program of Chinese Academy of Sciences (KSCX2-YW-JS401), the National Key Technology R\&D Program of China (2012BAJ24B01), the Major Science and Technology Program for Water Pollution Control and Treatment (2012ZX07209-003), and the Key Research Program of Chinese Academy of Sciences (KZZD-EW-11-1/3).

Conflict of interest The authors declare that they have no competing interests.

\section{References}

1. Semple KT, Doick KJ, Jones KC, Burauel P, Craven A, Harms H (2004) Defining bioavailability and bioaccessibility of contaminated soil and sediment is complicated. Environ Sci Technol 38:228a231a

2. Kahru A, Ivask A, Kasemets K, Pollumaa L, Kurvet I, Francois M, Dubourguier HC (2005) Biotests and biosensors in ecotoxicological risk assessment of field soils polluted with zinc, lead, and cadmium. Environ Toxicol Chem 24:2973-2982

3. Peltola P, Ivask A, Astrom M, Virta M (2005) Lead and $\mathrm{Cu}$ in contaminated urban soils: extraction with chemical reagents and bioluminescent bacteria and yeast. Sci Total Environ 350:194-203

4. Ivask A, Virta M, Kahru A (2002) Construction and use of specific luminescent recombinant bacterial sensors for the assessment of bioavailable fraction of cadmium, zinc, mercury and chromium in the soil. Soil Biol Biochem 34:1439-1447

5. Stocker J, Balluch D, Gsell M, Harms H, Feliciano J, Daunert S, Malik KA, Van der Meer JR (2003) Development of a set of simple bacterial biosensors for quantitative and rapid measurements of arsenite and arsenate in potable water. Environ Sci Technol 37: $4743-4750$ 
6. Tauriainen S, Karp H, Chang W, Virta M (1997) Recombinant luminescent bacteria for measuring bioavailable arsenite and antimonite. Appl Environ Microbiol 63:4456-4461

7. Ivask A, Rolova T, Kahru A (2009) A suite of recombinant luminescent bacterial strains for the quantification of bioavailable heavy metals and toxicity testing. BMC Biotechnol 9(1):41

8. Hou QH, Ma AZ, Li Y, Zhuang XL, Bai ZH, Zhang XK, Zhuang GQ (2014) Assessing the effect of phosphate and silicate on Cd bioavailability in soil using an Escherichia coli cadAp::luc-based whole-cell sensor. Environ Sci Process Impacts 16:890-896

9. Hou QH, Ma AZ, Zhuang XL, Bai ZH, Zhuang GQ (2004) The impacts of long-term different fertilization regimes on the bioavailability of arsenic in soil: integrating chemical approach with Escherichia coli arsRp::luc-based biosensor. Appl Microbiol Biotechnol 98:6137-6146

10. Ivask A, Francois M, Kahru A, Dubourguier HC, Virta M, Douay F (2004) Recombinant luminescent bacterial sensors for the measurement of bioavailability of cadmium and lead in soils polluted by metal smelters. Chemosphere 55:147-156

11. Liao VH, Chien MT, Tseng YY, Ou KL (2006) Assessment of heavy metal bioavailability in contaminated sediments and soils using green fluorescent protein-based bacterial biosensors. Environ Pollut 142:17-23

12. Harvey CF, Swartz CH, Badruzzaman ABM, Keon-Blute N, Yu W, Ali MA, Jay J, Beckie R, Niedan V, Brabander D, Oates PM, Ashfaque KN, Islam S, Hemond HF, Ahmed MF (2002) Arsenic mobility and groundwater extraction in Bangladesh. Science 298: 1602-1606

13. Campbell CD, Hird M, Lumsdon DG, Meeussen JCL (2000) The effect of EDTA and fulvic acid on $\mathrm{Cd}, \mathrm{Zn}$, and $\mathrm{Cu}$ toxicity to a bioluminescent construct (pUCD607) of Escherichia coli. Chemosphere 40:319-325

14. Turpeinen R, Salminen J, Kairesalo T (2000) Mobility and bioavailability of lead in contaminated boreal forest soil. Environ Sci Technol 34:5152-5156 